\title{
PERLINDUNGAN LINGKUNGAN DALAM PERSPEKTIF PRINSIP KEHATI-HATIAN (PRECAUTIONARY PRINCIPLE)
}

\author{
Elly Kristiani Purwendah \\ Fakultas Hukum Universitas Wijayakusuma Purwokerto \\ Email : elly kristiani@yahoo.co.id
}

\begin{abstract}
Abstrak
Dalam Undang-undang Nomor 23 Tahun 1997 (UUPPLH), tidak ada pengaturan secara spesifik mengenai prinsip kehati-hatian. Pasal 3 UUPPLH mengenai asas, tujuan dan sasaran pengelolaan lingkungan hidup hanya disebutkan asas tangung jawab negara, asas berkelanjutan dan asas manfaat yang bertujuan untuk mewujudkan pembangunan berkelanjutan yang berwawasan lingkungan hidup. Dalam UUPPLH prinsip kehati-hatian belum diatur secara jelas. Tidak diaturnya prinsip ini dalam UUPPLH bukan berarti bahwa Indonesia tidak mengenal prinsip kehati-hatian. Sebagaimana dilihat bahwa Indonesia telah melakukan ratifikasi 2 (dua) konvensi yaitu Ratifikasi Konferensi Rio de Jeneiro yang mengandung prinsip kehati-hatian melalui Undang-undang Nomor 5 Tahun 1995 tentang Pengesahan United Nations Conventons on Biological Diversity dan Undang-undang Nomor 6 Tahun 1996 tentang Pengesahan United Nations Framework Convention on Climate Change. Ratifikasi yang dilakukan ini menunjukkan bahwa Indonesia menganut prinip kehati-hatian dalam perlindungan dan pengelolaan lingkungan hidup.
\end{abstract}

Kata kunci : prinsip kehati-hatian, Konferensi Rio de Jeneiro, Perlindungan Hukum

\begin{abstract}
In Law Number 23 Year 1997 (UUPPLH), there is no specific regulation regarding the precautionary principle. Article 3 of the UUPPLH concerning the principles, objectives and targets of environmental management only states the principles of state responsibility, the principle of sustainability and the principle of benefits aimed at realizing sustainable development with an environmental perspective. In the UUPPLH the precautionary principle has not been clearly regulated. Not regulating these principles in the UUPPLH does not mean that Indonesia does not recognize the precautionary principle. As seen that Indonesia has ratified 2 (two) conventions, namely the Ratification of the Rio de Jeneiro Conference which contains the precautionary principle through Law Number 5 of 1995 concerning Ratification of the United Nations Conventons on Biological Diversity and Law Number 6 of 1996 concerning Ratification United Nations Framework Convention on Climate Change. This ratification shows that Indonesia adheres to the principle of prudence in environmental protection and management.
\end{abstract}

Keywords: precautionary principle, Rio de Jeneiro Conference, Legal Protection 


\section{Pendahuluan}

Wilayah laut Indonesia yang mencapai luas 3,11 juta $\mathrm{km}^{2}$ menyebabkan potensi sektor kelautan menjadi tidak ternilai (Siahaan, 2018), terutama dari sektor kekayaan alam lautnya. Potensi kekayaan laut menjadi sedemikian penting sebagaimana diprioritaskan oleh Indonesia dalam Konsep green economy dan blue economy yang bermuara pada pembangunan berkelanjutan sebagaimana disampaikan oleh Presiden RI saat memberikan sambutannya dalam Konferensi Rio+20 (United Nations Conference on Suistanable Development) di Rio de Jeneiro, Brasil pada tanggal 20-22 Juni 2012 (Lilley;1999).

Lingkungan laut merupakan bagian dari perekonomian suatu negara (Gore, 1995). Dengan panjang garis pantai sekitar $95.181 \mathrm{~km}$, perairan Indonesia memiliki potensi yang tinggi. Ukuran tersebut merupakan urutan kedua setelah Kanada sebagai Negara yang memiliki garis pantai kedua terpanjang di dunia. Nilai perekonomian dari laut ditaksir mencapai US\$3 triliun - US\$5 triliun atau setara dengan Rp. 36.000 triliun Rp. 60.000 triliun per tahun (Media Keuangan, Transparansi Informasi Kebijakan Fiskal, 2015). Angka ini belum termasuk potensi lain yang berasal dari kekayaan bioteknologi, wisata bahari maupun pengembangan transportasi laut. Potensi maritim Indonesia yang demikian besar ditangkap sebagai salah satu visi misi unggulan pada pemerintahan presiden Jokowi saat ini ( Selain itu, potensi besar ekonomi dan ekologi yang tersimpan sebagai negara maritim, potensi kerusakan alam yang dapat ditimbulkan akibat eksplorasi berlebihan yang dapat mengancam keberlanjutan pembangunan hendaknya juga mendapat perhatian. Untuk itu, saat ini pemerintah tengah mendorong kebijakan ekonomi maritim dengan model ekonomi biru. Pada dasarnya ekonomi biru menggabungkan pengembangan ekonomi dan pelestarian lingkungan.

Mengingat peran laut yang sangat strategis karena sebagian masyarakat mengandalkan laut sebagai mata pencaharian dan hidupnya, laut perlu mendapat perhatian utama dalam penegakkan hukumnya terutama dari akibat kerusakan ekosistem karena pencemaran. Sumber pencemaran laut dapat berasal dari : (1) pencemaran yang disebabkan atau berasal dari kapal; (2) pencemaran yang berasal oleh instalasi pengeboran minyak; (3) sumber pencemaran di darat; dan (4) pencemaran melalui udara. Permasalahan pencemaran minyak karena kecelakaan kapal (tanker) di Indonesia perlu mendapatkan perhatian serius berkenaan dengan hak menggugat (ius standi), pembuktian yang terkait dengan verifikasi ilmiah untuk menjelaskan hubungan kausal, penerapan asas ganti kerugian, cakupan dan luas isu lingkungan untuk menetapkan jumlah ganti rugi, dan kriteria pemulihan lingkungan terkait dengan sistem kebenaran formil yang dianut dalam sistem penuntutan ganti kerugian secara perdata.

Dalam kurun waktu 2011-2015 terjadi 4 (empat) pencemaran minyak di 
laut Cilacap. Pada tahun 2011 ada dua kasus pencemaran pada bulan Juli dan September oleh Kapal Super Tanker TT. Arenza XXVII dan Kapal MT. Medelin Atlas Belawan IMO 8717245, dan pada bulan April 2012 Kapal MV. Indo Baruna $\mathrm{V}$ mencemari lingkungan laut Cilacap. Terakhir di tahun 2015 pada bulan Mei 2015 Kapal tanker MT. Martha Petrol. Tuntutan ganti kerugian pencemaran minyak oleh kapal tanker di laut cilacap dilakukan oleh nelayan kepada PT. Pertamina melalui klaim langsung. Perhitungan ganti kerugian dihitung dalam jumlah kerugian langsung nelayan tidak bisa melaut selama terjadi pencemaran dikalikan jumlah nelayan yang terdaftar sebagai anggota Himpunan Nelayan Seluruh Indonesia (HNSI). Himpunan Nelayan Seluruh Indonesia (HNSI) Kabupaten Cilacap meminta ganti rugi Rp 40,7 miliar kepada PT Pertamina RU IV Cilacap akibat kebocoran minyak (http://berita.suaramerdeka.com).

Dalam penelitian ini akan dibahas tentang Perlindungan Lingkungan Dalam Perspektif Prinsip KehatiHatian (Precautionary Principle).

\section{Pembahasan}

Perlindungan Lingkungan Dalam Perspektif Prinsip Kehati-Hatian (Precautionary Principle)

Perlindungan Lingkungan

mendasarkan pada beberapa prinsip yaitu, pembangunan berkelanjutan (sustainable development), prinsip keadilan antar generasi (intergenartional equity) dan prinsip keadilan intragenerasi (intragenerational equity), prinsip pencemar membayar (polluter pays principle), prinsip pencegahan dini (principle of preventive action), prinsip kehati-hatian (precautionary principle), tanggung jawab negara (sovereign right) dan pertanggungjawaban lingkungan (environmental responsibility), prinsip partisipasi (acces to environmental information, public participation, environmental decisions, equal acces and non discrimination). Dari prinsipprinsip ini hanya tiga prinsip yang akan dibahas oleh penulis berkaitan dengan prinsip yang berlaku bagi ganti kerugian pencemaran minyak karena kecelakaan kapal tanker. Adapun prinsip yang akan dibahas adalah prinsip kehati-hatian (precautionary principle), prinsip pencemar membayar (polluter pays principle) dan pertanggungjawaban mutlak (strict liability). Keadilan ekologis dan keadilan sosial sebagai ukuran keadilan yang diharapkan dalam perlindungan lingkungan di Indonesia memiliki prinsip turunan. Peneliti akan membahas tiga prinsip turunan untuk pencapaian pada keadilan eko-sosial yaitu, precautionary principle yang diterapkan pada Deklarasi Rio 1992, polluter pays principle sebagaimana dianut dan dikembangkan pada tahun 1972 oleh negara-negara anggota Organisasi dan Kerjasama Ekonomi dan Pembangunan (Organization of Economic Cooperation and Development/OECD), dan strict liability sebagaimana yang diterapkan pada prinsip 21 Deklarasi Stockholm (Sands, 2003).

National Assembly Perancis pada tanggal 1 Maret 2005 mengadopsi 
Piagam Lingkungan Hidup (the Charter for the Environment) tahun 2004 dan mengintegrasikan piagam ini ke dalam Konstitusi Perancis (the Constitution of the French Fifth Republic) (Marrani, 2009). Piagam Lingkungan Hidup dijabarkan lebih lanjut dalam Pasal 10 yang berisi tentang berbagai hak dan kewajiban terkait pengelolaan lingkungan. Piagam ini menyatakan bahwa setiap orang memiliki hak atas lingkungan hidup yang sehat dan seimbang (Pasal 1), kewajiban kepada setiap orang untuk ikut serta dalam upaya pemeliharaan dan perbaikan lingkungan (Pasal 2), kewajiban untuk menghindari gangguan terhadap lingkungan atau, jika penghindaraan tidak memungkinkan untuk membatasi akibat gangguan tersebut (Pasal 3), mereka yang menyebabkan terjadinya kerusakan lingkungan memikul kewajiban untuk berkontribusi pada perbaikan kerusakan tersebut (Pasal 4), mewajibkan pembuat kebijakan untuk menerapkan asas kehati-hatian, the precautionary principle (Pasal 5), untuk mendukung pembangunan berkelanjutan dengan memadukan perlindungan dan pemanfaatan lingkungan hidup, pembangunan ekonomi serta kemajuan masyarakat (Pasal 6), hak atas informasi lingkungan, serta hak untuk dilibatkan dalam pengambilan keputusan (Pasal 7), pendidikan dan pelatihan terkait lingkungan hidup akan berkontribusi pada pelaksanaan hak dan kewajiban yang dimuat di dalam Piagam Lingkungan (Pasal 8), bahwa riset dan inovasi akan membantu pemeliharaan dan pemanfaatan lingkungan hidup
(Pasal 9), piagam lingkungan ini akan berfungsi sebagai acuan bagi penentuan kebijakan Perancis pada level Eropa dan Internasional (Pasal 10).

Menurut Assiddiqie (2009), pengadopsian piagam lingkungan di dalam konstitusi Perancis tidak sekedar penegasan tidak akan ada peraturan perundang-undangan yang bertentangan dengan piagam lingkungan, tetapi merupakan upaya untuk mengukuhkan prinsip-prinsip pengelolaan lingkungan yang merupakan bagian dari hukum serta memasukkan prinsip- prinsip pengelolaan lingkungan yang sudah diakui dalam hukum internasional ke dalam hukum nasional. Pasal 5 Piagam Lingkungan menyatakan bahwa : If the occurrence of damage has the potential affect the environment in a serious and irreversible manner, even though there may be scientific uncertainty, the public authorities should make sure by applying the precautionary principle and within the limits of their attributions, that procedures for evalution of the risks are followed and that provisional and proportionate measures are taken in order to ward off the damage (Jones dan R. Von Schomberg (eds), 2006).

Jika terjadinya kerusakan memiliki potensi mempengaruhi lingkungan secara serius dan tidak dapat diubah lagi, meskipun mungkin ada ketidakpastian ilmiah, otoritas publik harus memastikannya dengan menerapkan prinsip kehati-hatian dan dalam batas atribusi (pertalian) mereka, bahwa prosedur untuk melakukan evaluasi risiko telah diikuti dan tindakan yang bersifat sementara serta 
proporsional telah diambil untuk menangkal kerusakan.

Prinsip kehati-hatian ini menekankan pada bagaimana melakukan pencegahan agar tidak terjadi penurunan kualitas lingkungan hidup akibat pencemaran. Lebih jauh lagi, prinsip ini juga mengatur mengenai pencegahan agar tidak terjadi kerusakan lingkungan (Wibisana, 2008). Prinsip kehati-hatian digunakan sebagai upaya untuk mengantisipasi dan merespon kekawatiran yang timbul sebagai akibat possible harmful efect of technologies (kemungkinan akibat buruk dari penerapan ilmu pengetahuan dan tehnologi) yang mencemarkan atau membahayakan lingkungan hidup ( $\mathrm{J}$. Asshiddiqie). Prinsip kehati-hatian pertama kali diterapkan dalam kebijakan lingkungan hidup di Jerman pada tahun 1970-an, dan dikenal sebagai vorsorgeprinzip. Tujuan dari vorsorgeprinzip adalah untuk mencegah pencemaran dengan memperkirakan secara seksama potensi timbulnya pencemaran.

Disebutkan pula bahwa prinsip ini merupakan dasar bagi keberlanjutan sumber-sumber ekologi bagi generasi yang datang melalui penggunaan yang hati-hati atas sumber tersebut. Harald Hohmann menyatakan bahwa vorsorgeprinzip menghasilkan beberapa kewajiban sebagai berikut (Hohmann, 1994) :

1. kewajiban meminimasi sebabsebab yang mungkin dari kerusakan lingkungan dengan mengambil tindakan-tindakan berdasarkan tehnologi atau ilmu pengetahuan terbaru (state of technologi atau state of science and technology). jika bukti tentang kerusakan tersebut belum terkumpul, adanya kemungkinan saja tentang kerusakan tersebut telah cukup sebagai dasar kewajiban untuk melakukan proses recycle terhadap limbah yang dihasilkan;

2. kewajiban tentang penghindaran (avoidance) dihasilkannya limbah serta pengangkutan/penggunaan bahan-bahan berbahaya sejak proses produksi, serta kewajiban untuk melakukan proses recycle terhadap limbah yang dihasilkan;

3. pelarangan terhadap penurunan kondisi lingkungan saat ini (principle of the status quo preservation), artinya setiap orang didorong untuk tidak melakukan perusakan yang sebenarnya bisa dihindari (avoidable impairments). Status quo preservation juga berarti adanya kewajiban untuk membayar kompensasi terhadap kerusakan yang tidak bisa dihindari;

4. aspek lingkungan secara terus menerus harus diperhatikan dalam setiap perencanaan kebijakan. Hal ini berarti adanya kebutuhan yang lebih besar terhadap diberlakukannya Amdal;

5. pengelolaan lingkungan hidup yang mempertimbangkan aspek ekonomi dari alam, perlindungan dan sumber daya 
alam;

6. penggunaan sumber daya alam yang secara ekonomi efisien;

7. kewajban untuk membuat pembatasan terhadap penggunaan dan pemasaran bahan-bahan kimia.

Ticker dan Reffensperger menjelaskan bahwa asas kehati-hatian memiliki komponen-komponen turunan, baik secara yuridis maupun politis sebagai berikut (http://www.biotech_info.net) :

1. diambilnya langkah kehatihatian (precautionary action) sebelum kepastian ilmiah akan sebab dan akibat berhasil diperoleh;

2. ditetapkannya tujuan yaitu asas kehati-hatian mendorong terwujudnya perencanaan yang lebih didasarkan pada tujuan yang telah didefinisikan secara akurat dan bukan tujuan yang didasarkan pada skenario atau perhitungan risiko yang justru seringkali keliru dan bias;

3. penelusuran dan evaluasi alternatif-alternatif kebijakan. Artinya prinsip kehati-hatian lebih menekankan pada pertanyaan bagaimana mengurangi atau menghilangkan bahaya dan mencoba mencari semua alternatif untuk mencapai tujuan tersebut dan bukan didasarkan pada pertanyaan tingkat pencemaran yang seperti apa yang dapat dikatakan aman;

4. keputusan-keputusan yang dibuat dalam rangka penerapan asas kehati- hatian harus bersifat terbuka, demokratik, terinformasikan serta harus menyertakan pihak-pihak yang mungkin terkena dampak dari dikeluarkannya keputusan tersebut;

5. harus terdapat pengalihan beban pembuktian dimana pemrakarsa kegiatan menjadi berkewajiban untuk membuktikan bahwa kegiatannya tidak akan mengakibatkan bahaya bagi kesehatan dan keselamatan manusia dan ekosistem;

6. dikembangkannya metode dan kriteria pengambilan keputusan yang lebih demokratik dan seksama. Asas kehati-hatian masyarakat adanya pertimbangan ilmiah serta bukti/pertimbangan lain (non ilmiah) ketika menghadapi ketidak pastian, sehingga juga mensyaratkan adanya pertimbangan yang lebih seksama dan lebih banyak melibatkan partisipasi publik dalam pembuatan kebijakan.

Prinsip kehati-hatian merupakan perwujudan dari pengelolaan lingkungan yang didasakan pada pendekatan antisipatif. Pendekatan ini merupakan pendekatan tahap ketiga dari pendekatan yang dipakai untuk pengelolaan lingkungan (Treich, 2001). Prinsip kehati-hatian ditujukan sebagai arahan (guidance) bagi pengambilan keputusan dalam situasi ketidak pastian ilmiah (scientific uncertainty). Pada umumnya asas kehati-hatian 
dirumuskan dalam pernyataan bahwa apabila terdapat ancaman kerugian yang serius atau tidak bisa dipulihkan (threats of serious or irreversible damage), pengambil keputusan tidak dapat menggunakan kurangnya kepastian atau bukti ilmiah sebagai alasan untuk menunda dilakukannya upaya pencegahan atas ancaman tersebut. Prinsip kehati-hatian berperan besar untuk mengubah arah kebijakan dalam menghadapi bahaya yang serius tetapi masih bersifat tidak pasti. Apabila selama ini para pengambil kebijakan seringkali abai untuk melakukan tindakan pencegahan, dengan prinsip kehati-hatian potensi bahaya tidak lagi diabaikan hanya berdasarkan alasan bahwa bahaya tersebut masih belum jelas dan diliputi oleh ketidakpastian ilmiah (Geistfeld, 2001).

Prinsip kehati-hatian yang dikenal pertama kali di Jerman sebagai sebuah asas pengelolaan lingkungan di dalam hukum lingkungan Jerman dengan istilah voorsorgeprinzip yang berarti foresight (tinjauan masa depan) dan taking care (berhati-hati). Voorsorgeprinzip mewajibkan negara untuk menghindari terjadinya kerusakan/pencemaran lingkungan dengan melakukan perencanaan secara hati-hati. Prinsip ini juga menjadi pembenaran bagi program pencegahan dan penanggulangan pencemaran secara besar- besaran melalui pemberlakuan tehnologi terbaik (best available technology) untuk meminimalisasi kemungkinan terjadinya pencemaran (A. Jordan dan T. O'Riordan, 1999). Prinsip ini selanjutnya diadopsi dalam berbagai deklarasi atau perjanjian tentang perlindungan lingkungan laut di Eropa. Pencegahan ini dilakukan pada kegiatan dan/atau usaha yang belum diketahui seberapa luas dan besar kerugian dan/atau kerusakannya. Pencegahan dilakukan dengan melakukan langkah nyata, meskipun belum adanya bukti ilmiah mengenai seberapa luas dan besar akibat yang mungkin terjadi. Namun prinsip ini hanya akan berlaku pada perkiraan yang berdampak serius dan kerusakan yang tidak dapat dipulihkan kembali terhadap lingkungan hidup. Prinsip ini berkembang begitu cepat di seluruh belahan bumi sebagai prinsip yang sudah jelas kebenarannya (axiomatic) sebagai prinsip dalam menjaga kelestarian lingkungan hidup (David Freestone dan Ellen Hey, 1996).

Formulasi prinsip kehati-hatian pertama kali muncul dalam The 1984 Bremen Declaration yang diadopsi pada the First International Conference on the Protection of the North Sea. Deklarasi ini menyatakan bahwa : "...damage to the marine environment can be irreversible or remediable only at considerevly expense and over long periods and... therefore, coastal states... must not wait for proof of harmfull effects before taking action “...kerusakan pada lingkungan laut bisa jadi tidak dapat diubah atau dapat diperbaiki hanya dengan biaya yang besar dan jangka waktu yang panjang dan... oleh karena itu, negara-negara pantai... tidak boleh menunggu adanya bukti ditemukannya efek yang berbahaya sebelum mengambil tindakan.

Pengakuan prinsip ini dinyatakan 
kembali dalam The 1987 London Declaration yang diadopsi pada the Second International Conference on the Protection of the North Sea. The 1990 Hague Declaration yang diadopsi pada the Third International Conference on the Protection of the North Sea, The 1995 Esjberg Declaration yang diadopsi pada the Fourth International Conference on the Protection of the North Sea, serta The 2012 Bergen Declaration the Fifth International Conference on the Protection of the North Sea. Berpangkal pada deklarasi-deklarasi tersebut, asas kehati-hatian kemudian diadopsi dalam The 1992 Convention on the Protection of the Marine Environment of the Baltic Sea Area, The 1992 Convention for the Protection of the Marine Environment of the North-East Altantic (OSPAR Convention), The 1995 Barcelona Convention for the Protection of the Marine Environment and the Coastal Region of the Mediterranean (The 1995 Barcelona Convention), The 1996 Izmir Protocol on the Prevention of Pollution of the Mediterranean Sea by Transboundary Movements of Hazardous Wastes and their Disposal, dan The 2002 Valletta Protocol

Concerning Cooperation in Preventing Pollution from Ships and in ases of Emergency. Diluar rezim perlindungan laut, asas kehati-hatian telah dimasukkan di dalam World Charter of Nature (Piagam Lingkungan Dunia) yang diadopsi oleh Majelis Umum PBB pada tahun 1982. Piagam Lingkungan Dunia merumuskan asas kehati-hatian sebagai berikut :

1. activities which are likely to cause irreversible damage to nature shall be avoided;

2. activities which are likely to pose a significant risk to nature shall be preceded by an exhaustive examination; their proponents shall demonstrate that expected benefit outweigh potential damage to nature, and where potential adverse effects are not fully understood activities should not proceed.

a. Kegiatan-kegiatan yang mungkin menyebabkan kerusakan permanen terhadap alam harus dihindari;

b. Kegiatan-kegiatan yang mungkin menimbulkan risiko yang signifikan terhadap alam harus didahului dengan pemeriksaan yang mendalam; para pendukungnya harus menunjukkan bahwa manfaat yang diharapkan lebih besar daripada potensi kerusakan alamnya, dan jika potensi efek sampingnya tidak sepenuhnya dipahami, kegiatan tidak boleh dilanjutkan.

Pada Tahun 1992 merupakan tahun yang penting bagi perkembangan asas kehati-hatian. Pada tahun ini, prinsip kehati-hatian diadopsi dalam Maastricht Treaty, Konvensi Helskinsi, United Nations Framework Convention on Climate Change/UNFCCC, Convention on Biological Diversity/CBD dan Deklarasi Rio. Setelah tahun 1992 prinsip kehatihatian semakin luas diadopsi oleh berbagai perjanjian internasional tentang lingkungan hidup. Berikut ini adalah dokumen internasional sejak tahun 1992 yang memuat asas kehatihatian : 1. The 1992 Maastricht Treaty 
Volume 1, Nomor 2 Oktober 2019

ISSN : 2656-9639 (Cetak)

ISSN : 2684-9046 (Online)

menyatakan bahwa kebijakan lingkungan dari komunitas Eropa harus ditujukan untuk mencapai tingkat perlindungan yang tinggi dan harus didasarkan pada asas kehati-hatian (Maastricht Treaty); 2. The 1992 Helskinki Convention on the Protection and Use of Transboundary Watercourses and International Lake, yang mengakui asas kehati-hatian sebagai asas yang melandasi upaya untuk mencegah, mengendalikan dan mengurangi dampak negatif dari sumber air lintas negara dan danau internasional, disamping juga untuk menjamin konversi dan pemulihan ekosistem; Prinsip kehati-hatian menjadi prinsip yang penting dan diadopsi dalam berbagai kebijakan setelah dituangkan dalam Deklarasi Rio 1992 yang dihasilkan pada The United Nations Conference on Environment and Development (UNCED) di Rio de Jeneiro, Brazil tanggal 3-14 Juni 1992. Prinsip 15 Deklarasi Rio 1992 menyatakan bahwa :

In order to protect the environment, the precautionary approach shall be widely appplied by States according to their capabilities. Where there are threats of serious or irreversible damage, lack of full scientific certainty shall not be used as a reason for postponing cost-effective measures to prevent environmental degradation" (David Freestone, 1994).

Untuk melindungi lingkungan, pendekatan kehati-hatian harus diaplikasikan secara luas oleh Negaranegara sesuai dengan kemampuan mereka. Di mana ada ancaman kerusakan serius atau yang tidak dapat dipulihkan, kurangnya kepastian ilmiah yang penuh tidak boleh digunakan sebagai alasan untuk menunda langkahlangkah yang hemat biaya untuk mencegah degradasi lingkungan.

Prinsip kehati-hatian menunjukkan bahwa kehati-hatian perlu dilakukan oleh negara dalam pembuatan kebijakan. Kegiatan yang memiliki kemungkinan untuk menyebabkan dampak yang serius dan tidak dapat dipulihkan inilah yang dalam prinsip ini harus dicegah. Dalam hal ini kurangnya kepastian ilmiah tidaklah dapat dijadikan alasan untuk melakukan penundaan bagi upaya pencegahan.

Laporan dari United Nation Economic and Social Comission for Asia and the Pasific (UNESCAP) menyatakan bahwa, "Believe that, in order to archieve sustainable development policies must be based on the precautionary principle". Konsep pencegahan dini ini memang telah diterima dan diterapkan secara luas dalam berbagai aspek kehidupan. Dalam kaitannya dengan prinsip kehati-hatian ini dinyatakan bahwa, "Science does not always provide the insights needed to protect the environment effectively, and that undesirable effect my result if measures are taken only when science does provide such insights" (Ilmu pengetahuan tidak selalu menyediakan wawasan yang diperlukan untuk melindungi lingkungan secara efektif, dan efek yang tidak diinginkan tersebut bisa terjadi jika tindakan yang diambil hanya ketika sains memberikan wawasan tersebut). Dikatakan lebih lanjut bahwa; The essence of precautionary concept, the 
precautionary principle, is that once a risk has been identified, the lack of scientific proof of cause and effect shall not be used as a reason for not taking action to protect the environment.

Inti dari konsep kehati-hatian, prinsip kehati-hatian, adalah bahwa sekali risiko telah diidentifikasi, kurangnya bukti ilmiah mengenai sebab dan akibatnya tidak boleh digunakan sebagai alasan untuk tidak mengambil tindakan untuk melindungi lingkungan. Dari penjelasan tersebut diatas, penerapan prinsip kehati-hatian meliputi beberapa unsur antara lain :

1. once risk has been identified yang berarti bahwa, apabila telah

teridentifikasi kerugian yang mungkin timbul;

2. where there are threats of serious or irreversible damage yang berarti bahwa, apabila ada ancaman yang serius atau ancaman tersebut tidak dapat dipulihkan kembali akibatnya sehingga berdampak selamanya pada lingkungan. Serious dan irreversible damage tidak menentu ukurannya dan harus dilihat kasus perkasus;

3. lack of scientitic certainty yang berarti bahwa, apabila terdapat kurangnya kemampuan untuk mengukur kemungkinan akan akibat atau dampak yang akan terjadi, sehingga terdapat uncertainty atau ketidak yakinan atas ketidak pastian mengenai besar dan luasnya dampak yang akan terjadi.

Dalam Undang-undang Nomor 23 Tahun 1997 (UUPPLH), tidak ada pengaturan secara spesifik mengenai prinsip kehati-hatian. Pasal 3 UUPPLH mengenai asas, tujuan dan sasaran pengelolaan lingkungan hidup hanya disebutkan asas tangung jawab negara, asas berkelanjutan dan asas manfaat yang bertujuan untuk mewujudkan pembangunan berkelanjutan yang berwawasan lingkungan hidup. Dalam UUPPLH prinsip kehati-hatian belum diatur secara jelas. Tidak diaturnya prinsip ini dalam UUPPLH bukan berarti bahwa Indonesia tidak mengenal prinsip kehati-hatian. Sebagaimana dilihat bahwa Indonesia telah melakukan ratifikasi 2 (dua) konvensi yaitu Ratifikasi Konferensi Rio de Jeneiro yang mengandung prinsip kehati-hatian melalui Undangundang Nomor 5 Tahun 1995 tentang Pengesahan United Nations Conventons on Biological Diversity dan Undang-undang Nomor 6 Tahun 1996 tentang Pengesahan United Nations Framework Convention on Climate Change. Ratifikasi yang dilakukan ini menunjukkan bahwa Indonesia menganut prinip kehatihatian dalam perlindungan dan pengelolaan lingkungan hidup.

Kritik terhadap prinsip kehatihatian adalah terdapat perbedaan rumusan prinsip kehati-hatian. Wiener mengelompokkan rumusan asas kehatihatian ke dalam tiga kelompok yaitu, "uncertainty does not justify inaction", "uncertainty risk justifies action", dan "shifting the burden of proof". Menurut Wiener, rumusan uncertainty does not justify action merupakan versi yang paling lunak, sedangkan shifting the burden of proof merupakan versi yang paling keras dari asas kehati-hatian (D.J. Paustenbach, 2002). Asas kehatihatian sebagaimana tercantum dalam Pasal 5 Piagam Lingkungan Perancis 
menyatakan bahwa apabila terdapat ancaman kerusakan yang serius dan tidak bisa dipulihkan, maka pejabat publik memiliki kewajiban untuk memastikan, berdasarkan penerapan asas kehati-hatian dan kewenangan yang dimilikinya, bahwa prosedur penilaian risiko (risk assessment) (J.R. May, 2005-2006) akan diikuti serta bahwa upaya provisional dan proporsional akan diambil untuk mencegah kerusakan tersebut. Beberapa hal yang perlu diperhatikan adalah :

1. kewajiban melaksanakan asas kehati-hatian ini ditujukan bagi pejabat publik (public authority) dan bukan bagi masyarakat umum;

2. penerapan asas kehati-hatian ini dipicu oleh adanya potensi kerusakan lingkungan yang bersifat serius dan irreversible;

3. penerapan asas kehati-hatian mewajibkan dilakukannya prosedur penilaian risiko (risk assesment) oleh pejabat publik;

4. tindakan kehati-hatian bersifat sementara (provisional);

5. asas kehati-hatian harus ditetapkan bersama-sama dengan asas proporsionalitas.

\section{Kesimpulan}

Dalam Undang-undang Nomor 23 Tahun 1997 (UUPPLH), tidak ada pengaturan secara spesifik mengenai prinsip kehati-hatian. Pasal 3 UUPPLH mengenai asas, tujuan dan sasaran pengelolaan lingkungan hidup hanya disebutkan asas tangung jawab negara, asas berkelanjutan dan asas manfaat yang bertujuan untuk mewujudkan pembangunan berkelanjutan yang berwawasan lingkungan hidup. Dalam UUPPLH prinsip kehati-hatian belum diatur secara jelas. Tidak diaturnya prinsip ini dalam UUPPLH bukan berarti bahwa Indonesia tidak mengenal prinsip kehati-hatian. Sebagaimana dilihat bahwa Indonesia telah melakukan ratifikasi 2 (dua) konvensi yaitu Ratifikasi Konferensi Rio de Jeneiro yang mengandung prinsip kehati-hatian melalui Undangundang Nomor 5 Tahun 1995 tentang Pengesahan United Nations Conventons on Biological Diversity dan Undang-undang Nomor 6 Tahun 1996 tentang Pengesahan United Nations Framework Convention on Climate Change. Ratifikasi yang dilakukan ini menunjukkan bahwa Indonesia menganut prinip kehatihatian dalam perlindungan dan pengelolaan lingkungan hidup.

\section{Daftar Pustaka}

A. Jordan dan T. O'Riordan, 1999, The Precautionary Principle in Contemporary Environmental Policy and Politics dalam C. Raffensperger dan J. Tickner (eds), 1999, Protecting Public Health and the Environment: Implementing the Precautionary Principle, Island Press, Washington DC.

Asshiddiqie, J., 2009, Green Constitution: Nuansa Hijau Undang-undang dasar Negara Republik Indonesia Tahun 1945, Rajawali Press, Jakarta.

B. Wiener, Precaution in a Multirisk World, dalam D.J. Paustenbach, 
2002, Human and Ecological Risk Assessment: Theory and Practise, John Wiley and Sons, New York.

D. Marrani, 2009, Human Rights and Environmental Protection: The Pressure of the Carter for the Environment on the French Administrative Courts, Sustainable Development Law and Policy, Vol. 10. Hlm. 52.

David Freestone dan Ellen Hey, 1996, Origins and Development of the Precautionary Principle, dalam The Precautionary Principle and International Law, The Challenge of Implementation, Hague, Kluwer Law international.

David Freestone, 1994, The Road from Rio: International Environmental Law after the Earth Summit, Journal of Environmental Law 6.

Harald Hohmann, 1994, Precautionary Legal Duties and Principles of Modern International Law: The precautionary principle: International Environmental Law between Exploitation and Protection, Graham\&Trotman, London.

J.R. May, 2005-2006, Constituting Fundamental Environmental Rights Worldwide, Pace Environmental Law Review, Vol. 23.

Joel Tickner dan Carolyn Reffensperger, The precautionary principle in Action: A Handbook, first edition, http://www.biotech_info.net/han dbook.pdf.

M. Geistfeld, 2001, Implementing the
Precautionary Principle, Environmental Law Reporter, Vol. 31.

M.R.A.G. Wibisana, 2008, Law and Economic Analysis of the Precautionary Principle, Disertasi Doktor, Maastricht University, Maastricht.

Mangku, D. G. S. (2010). Pelanggaran terhadap Hak Kekebalan Diplomatik (Studi Kasus Penyadapan Kedutaan Besar Republik Indonesia (KBRI) di Yangon Myanmar berdasarkan Konvensi Wina 1961). Perspektif, 15(3).

Mangku, D. G. S. (2011). Peluang dan tantangan ASEAN dalam penyelesaian sengketa Kuil Preah Vihear di perbatasan Kamboja dan Thailand. Pandecta: Research Law Journal, 6(2).

Mangku, D. G. S. (2012). Suatu Kajian Umum tentang Penyelesaian Sengketa Internasional Termasuk di Dalam Tubuh ASEAN. Perspektif, 17(3).

Mangku, D. G. S. (2013). Kasus Pelanggaran Ham Etnis Rohingya: Dalam Perspektif ASEAN. Media Komunikasi FIS, 12(2).

Mangku, D. G. S., \& Itasari, E. R. (2015). Travel Warning in International Law Perspective. International Journal of Business, Economics and Law, 6(4).

Nicholas Treich, 2001, What is the Economic Meaning of the Precautionary Principle?, The Geneva Papers on Risk and Insurance, Vo. 26, No. 3, 2001. 
Volume 1, Nomor 2 Oktober 2019

ISSN : 2656-9639 (Cetak)

ISSN : 2684-9046 (Online)

O. Godard, The Precautionary Society (ICONPROCS 2019). Principle and Catastrophism on Atlantis Press.

Tenterhooks: Lessons from a Constitutional Reform in France, dalam E. Fisher, J. Jones dan R. Von Schomberg (eds), 2006, Implementing the Precautionary Principle: Perspective and Prospects, Edward Edgard, Cheltenham.

Parthiana, I Wayan. 2002. Hukum Perjanjian Internasional Bagian 1. Bandung: CV. Mandar Maju.

Parthiana, I Wayan. 2014. Hukum Laut Internasional dan Hukum Laut Indonesia. Bandung: Yrama Widya.

Periani, A., \& Mangku, D. G. S. Implementation Of Asean Convention On Counter Terrorism In Eradication Of Terrorism That Happens In The South Asia Area.

Phillipe Sands, 2003, Principle of International Environmental Law, Second Edition, Cambridge Cambridge University Press, United Kingdom.

Purwanto, H., \& Mangku, D. G. (2016). Legal Instrument of the Republic of Indonesia on Border Management Using the Perspective of Archipelagic State. International Journal of Business, Economics and Law, 11(4).

Purwendah, E., Mangku, D., \& Periani, A. (2019, May). Dispute Settlements of Oil Spills in the Sea Towards Sea Environment Pollution. In First International Conference on Progressive Civil 